\title{
Food Security Risk Level Assessment: A Fuzzy Logic based Approach
}

Muhd Khairulzaman Abdul Kadir, E.L. Hines, Kefaya Qaddoum, Rosemary Collier, Elizabeth Dowler, Wyn Grant, Mark Leeson, Daciana Iliescu, Arjunan Subramanian, Keith

Richards, Yasmin Merali and Richard Napier

University of Warwick, United Kingdom

Name and address for correspondence Author:

\author{
Muhd Khairulzaman Abdul Kadir \\ Intelligent Systems Engineering Laboratory Research Group \\ School of Engineering \\ University of Warwick \\ Coventry \\ CV4 7AL \\ United Kingdom \\ Email: M.K.Abdul-Kadir@warwick.ac.uk \\ Phone: +44(0)78 53975736 \\ Office Fax: +44(0)24 76418922
}




\title{
Food Security Risk Level Assessment: A Fuzzy Logic based Approach
}

\author{
Muhd Khairulzaman Abdul Kadir, E.L. Hines, Kefaya Qaddoum, Rosemary Collier, \\ Elizabeth Dowler, Wyn Grant, Mark Leeson, Daciana Iliescu, Arjunan Subramanian, Keith \\ Richards, Yasmin Merali and Richard Napier \\ University of Warwick, United Kingdom
}

\begin{abstract}
A fuzzy logic (FL) based food security risk level assessment system is design in this paper. Three inputs - yield, production and economic growth, were used to predict the level of risk associated with food supply. A number of previous studies have related food supply with risk assessment for particular types of food, but none the work was specifically concerned with how the wider food chain might be affected. The system we describe here uses the Mamdani method. The resulting system can assess risk level against three grades: severe, acceptable and good. The method is tested with UK (United Kingdom) cereal data for the period from 1988 to 2008. The approach is discussed on the basis that it could be used as a starting point in developing tools which may either assess current food security risk or predict periods or regions of impending pressure on food supply.
\end{abstract}

Keywords: food security, fuzzy logic, risk level, intelligent system 


\section{1 - Introduction}

In the context of this work, risk will be defined as the probability of a negative function which attempts to describe the possible adverse pressure on the system caused by a hazard (Meltzer et al. 2003; Xiaojun et al. 2008). Risk assessment has become more and more important from a research perspective either in term of an area of application or from the society itself, and is considered a valuable tool in most studies in which food security projections are linked to decision support systems. Most of such work will indicate risk levels which are either minor or major, but are otherwise mainly qualitative. Advanced risk assessment protocols are used in many areas as aids to decision making. For example: in the construction industry, where the practise is comparatively mature, the techniques of Fault tree analysis, event tree analysis, Monte Carlo analysis, scenario planning and sensitivity analysis are prevalent (Peihong and Jiaqiong 2009).

Although there are many accepted risk assessment methods, many scientists and engineers are trying to improve the techniques so as to produce more accurate results. For example, the Analysis Hierarchy Process (AHP) decision making technique in the construction industry is improving risk assessment, but it has a drawback in that it can only deal with definite scales and measured commodities. The problem is, it cannot solve involve uncertainties and subjectivities (Peihong and Jiaqiong 2009). The Fuzzy Logic (FL) technique is an alternative technique that is becoming more frequently used to improve the performance of risk assessment systems (Zeng et al. 2007). FL can work effectively with many parameters and non-uniform variables suggesting that it can deal with most of the drawbacks in previous and more conventional techniques. The application of FL to predict challenges to food security are evaluated in this paper. 


\section{1 - Food security}

Food security is a broad area. On the macro scale, it has largely been relegated to international agencies. On the micro scale it has been devolved to national government agencies. However, in the last few years, rising commodity prices combined with agricultural reactions or contributions to climate change have contributed to its moving to centre-stage in policy analysis and interventions (Initiative 2009). The definition of food security is much debated; for the purposes of our research it was taken in the usually understood sense of "Food security exist when all people, at all times, have physical and economic access to sufficient, safe and nutritious food that meets their dietary needs and food preferences for an active and healthy life” (Organization 2006).

Some influential authors (Peihong and Jiaqiong 2009), indicate that the main factors in food security, at a national level are: food availability, according to the needs of the person (encompassing food prices, distance to shops, available income to spend on food); food affordability, nutritional contents, safety, food system resilience and consumer confidence (DEFRA 2010). Each of these factors can be represented by various indicators such as trends in global output of food (from farm to end products), land-use changes, diversity of supply, energy dependency of food chain, income factors and trends in food-borne pathogen cases where monitoring could be difficult due to long term effect from pathogenic such as Sammonella, Listeria, E. Coli O157 and Campylobacter (DEFRA 2010). Each of the indicators is related to the food chain processes (Ding et al. 2007) and each is evaluated or recorded from imprecise inputs. Most of the factors are not fully controllable where it is just not about the resilience or success of the 'food chain'- it also about consumer demand and the supply channel such as retail outlets and restaurants; therefore, it is difficult to use a conventional data-based approach which would require precise information to describe every single interaction. 
In contrast, FL systems offer a number of advantages compared to conventional databased approaches. Some of the main advantages are that they can be easily implemented and tuned, and they uses 'IF-THEN' rules that will generate output based on imprecise inputs. However, to make it more effective, FL systems require a lot of data parameter or expert information. There are a few previous example of FL being applied to specific elements of the food chain and related food security; for example China's grain security warning study (Jianling and Yong 2010a; b; Yong and Jianling 2010), crop control (M. Ahmend 1999) and Gari fermentation plant (Odetunji and Kehinde 2005).

In this paper we are concerned with examining the risk of national food insecurity by using a FL technique. The system was designed such that it is able to determine the overall level of prevailing food security risk by monitoring various, but independent risk elements within food supply systems. The rest of this paper is organized as follows: section 2 presents the Methodology, section 3 is Results and Discussions and finally section 4 represents the conclusions.

\section{2 - Methodology}

Lofti Zadeh (1965) is attributed with being the key contributor to the modern era of FL and its applications. The methodology was introduced to cope with vagueness in linguistics and the challenges of expressing human 'knowledge' in a natural, but generally imprecise way (Haslum et al. 2007). Most of the applications that involved FL were based on its reasoning process and its ability to express outputs in understandable terms (Perrot et al. 2006). Given the multiple complexities involved in evaluating risk in food security and food supply chains, a FL model was attempted by Xiaojun Wang, et al. (Xiaojun et al. 2008). This principle is applied at the input to the level of risk on food security in the UK (figure 1). 


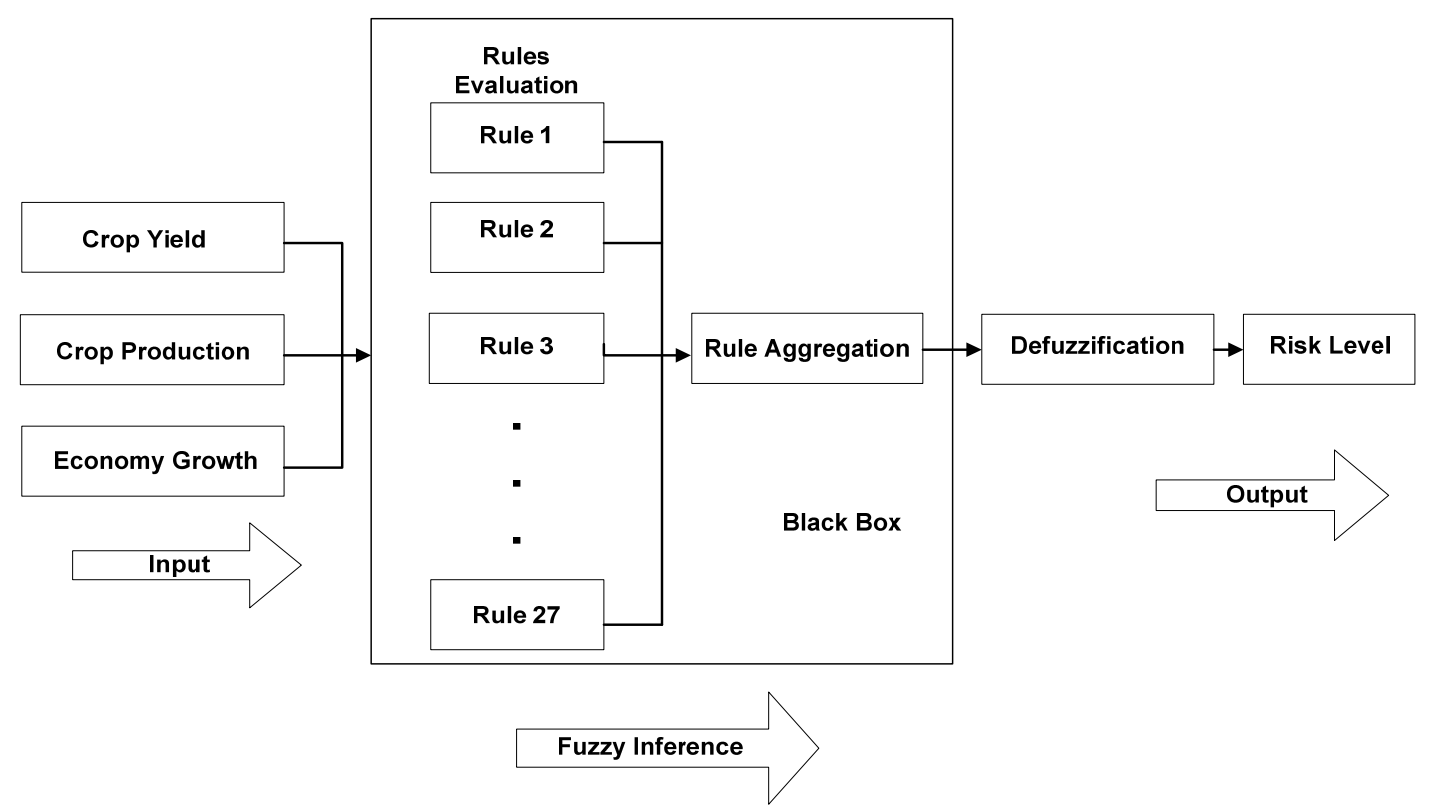

Figure 1: Basic block diagram of our FL system

Our model in figure 1 uses: UK crop yield (defined as the monthly farm gate crop output), UK crop production (defined as crops which are processed into food products) and UK economic growth (defined as growth as percentage gross domestic, GDP) as the inputs to determine the risk level, which is the system output. The work by Monty P. Jones (Jones) concerning a study in subSaharan Africa (DEFRA 2009; 2010), showed that the first two inputs are good indicators of overall food availability. The paper also indicated that economic growth was strongly associated with the food security. Our objective is to use the FL technique to turn these semi-precise or qualitative measures into quantitative assessment outcomes. Each of the input and output process is performed in a FL black box. In this scenario, the process which is conducted inside the black box is fuzzy, an inference process. 
The first step in the fuzzy inference process is called a fuzzification process. It involves rule evaluation and aggregation using the Mamdani method. This method was selected because it is widely accepted and suited to capturing expert knowledge. If it is compared to the Mamdani method, Sugeno method uses the singleton rule output which only work well with linear technique (J.S.R. Jang 1997; Negnevitsky 2005). A very important part of this process is how the fuzzy sets are delimited. Rules need to be set based on grades of importance of inputs and outputs of the system being modelled (Huey-Ming 1996).

In our model, each of the inputs has been chosen to have 3 fuzzy sets that will determine the degree of each of the input as shown in table 1 . The ranges refer to the normalization of the corresponding crisp input value based on its universe of discourse. For this study, cereal data is used as an example for the type of crop we are modelling. Let us consider them in turn.

1) For cereal crop yield, the input value will be derived from high yield, medium yield and low yield as its fuzzy set which was determine based on the highest and lowest value and divided it into 3 lots. This approach also applies in the case of crop production and economic growth as shown in figure 1 . In the case of the output, the fuzzy set function is shown in table 2 which indicates the fuzzy sets and their ranges. The range of each inputs and output are determined by referring to the data value in UK as in section 2.1 where the maximum and minimum value of each input parameter for the period of years is specified. 


\begin{tabular}{|c|c|c|}
\hline Input & Fuzzy set & Range \\
\hline Cereal Yield & High - Medium - Low & $0-1$ \\
\hline Cereal Production & High - Medium - Low & $0-1$ \\
\hline Economic Growth & High - Medium - Low & $0-1$ \\
\hline
\end{tabular}

Table 1: The input fuzzy sets and theirs range

\begin{tabular}{|c|c|c|}
\hline Output & Fuzzy set & Range \\
\hline Risk Level & Good -Acceptable - Severe & $0-1$ \\
& & \\
\hline
\end{tabular}

Table 2: The output fuzzy sets and theirs range

In the design and implementation of a FL system (Negnevitsky 2005), the option exists to choose which of the three most popular membership functions to use; triangular, Gaussian or trapezoidal function. In this work, initially we chose to use the triangular function for the inputs and a trapezoidal function for the outputs of our model. We will explore the other options later if necessary. Using triangular and trapezoidal functions means that the performance rate of the fuzzification process will be very fast, although the level of accuracy will be lower than with either of the other membership functions; the normal speed versus complexity scenario (Xie et al. 1998).

The next step is to determine the rule relationship for each of the inputs and the output. This is where the Bayessian rules (Negnevitsky 2005) and it is also called as 'If...then' rules was used. Given 3 inputs and 3 membership functions the numbers of rules that can be generated is $3^{3}=27$ rules (Table 3 ). 


\begin{tabular}{|c|c|c|c|}
\hline \multicolumn{3}{|c|}{ Input } & \multirow{2}{*}{$\begin{array}{c}\text { Output } \\
\text { Food Security Risk Level }\end{array}$} \\
\hline Cereal Yield & Cereal Production & Economic Growth & \\
\hline High & High & High & Good \\
\hline High & High & Medium & Good \\
\hline High & High & Low & Acceptable \\
\hline High & Medium & High & Acceptable \\
\hline High & Medium & Medium & Good \\
\hline High & Medium & Low & Acceptable \\
\hline High & Low & High & Severe \\
\hline High & Low & Medium & Severe \\
\hline High & Low & Low & Severe \\
\hline Medium & High & High & Severe \\
\hline Medium & High & Medium & Acceptable \\
\hline Medium & High & Low & Acceptable \\
\hline Medium & Medium & High & Acceptable \\
\hline Medium & Medium & Medium & Good \\
\hline Medium & Medium & Low & Good \\
\hline Medium & Low & High & Severe \\
\hline
\end{tabular}




\begin{tabular}{|c|c|c|c|}
\hline Medium & Low & Medium & Acceptable \\
\hline Medium & Low & Low & Severe \\
\hline Low & High & High & Severe \\
\hline Low & High & Medium & Severe \\
\hline Low & High & Low & Severe \\
\hline Low & Medium & High & Severe \\
\hline Low & Medium & Medium & Acceptable \\
\hline Low & Medium & Low & Acceptable \\
\hline Low & Low & High & Severe \\
\hline Low & Low & Medium & Severe \\
\hline Low & Low & Low & Acceptable \\
\hline
\end{tabular}

Table 3: Rule list showing the connection between the inputs and the output

Here is an example of the fuzzy rule which relates the input and the output by using the 'if and then' technique:-

'If cereal yield is high and cereal production is high and economic growth is high then the risk level will be good.'

A similar rule statement will apply for the remaining 26 rules in table 3. 
Next, in the rule evaluation, an AND function is used as fuzzy operator to compare each of the inputs. This function also known as the algebraic product function (Negnevitsky 2005).

For our example, to get the crop value (crisp value), the fuzzy output value needs to be defuzzifed or be aggregate at the rule output (A.S. Sodiya 2007). In order to perform the defuzzification, a number of different approaches maybe used; see for example (J.-S.R. Jang 1997; Negnevitsky 2005). Here, we use either the centre of gravity or centroid as the defuzzification technique.

\section{1 - Testing the system with the data for the input}

In order to test the system the data is taken from an online data base - World Bank (Bank 2010) and Food and Agriculture Organization (FAO) (FAO 2010). The data which we used relates to cereal yield and cereal production taken from the year 1988 to 2008 because the longer the period of data, the higher the testing value we can analyse and study for this model. The cereal yield unit is in hectogram/hectare $(\mathrm{Hg} / \mathrm{Ha})$ and the cereal production unit is in tons. The same goes for the economic growth data which is based on growth as a percentage of GDP for the period. All the data have been normalized because the system input fuzzy set is 0 to 1 . We will present the results and discuss them in the next section of this paper. 


\section{3 - Results and discussions}

The simulation was run in the Matlab 2010 environment and figure 2 shows the fuzzy model of the risk assessment system based on the Mamdani method. The system uses the 27 fuzzy rules and the centroid defuzzification to defuzzify the output.

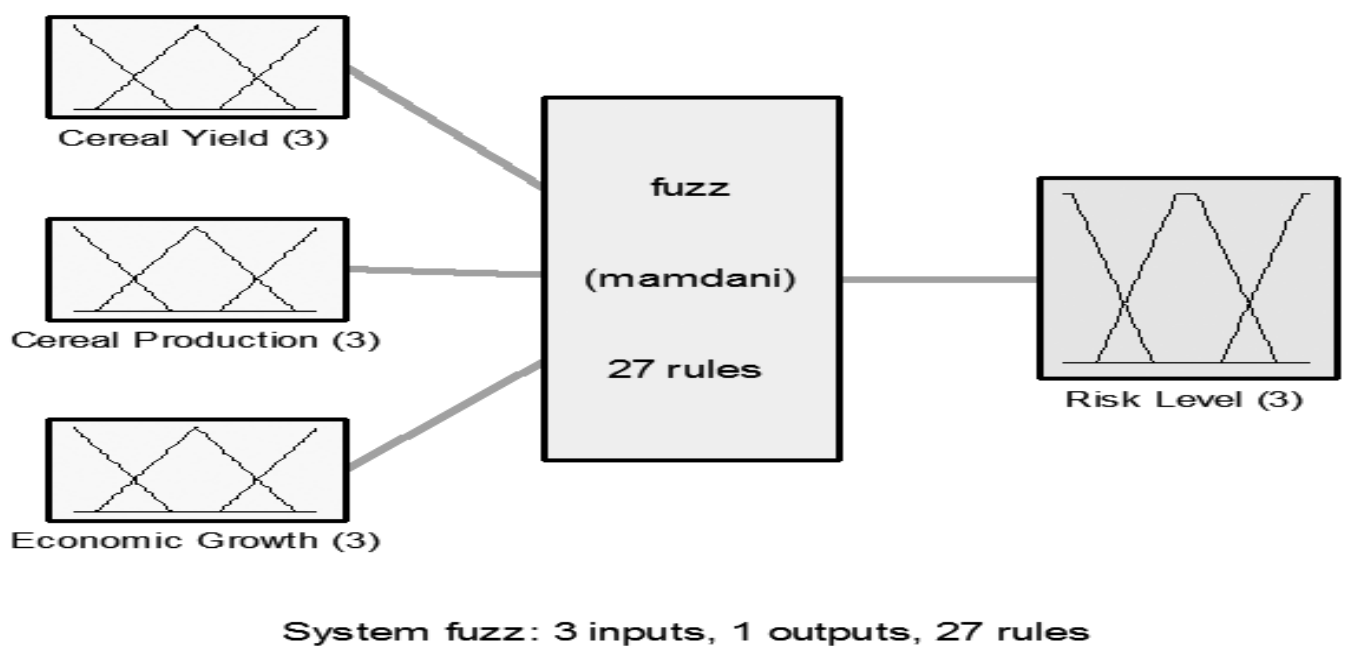

Figure 2: The model for our FL-based risk assessment system

The overall result of the system will be determined by the relationship between the 3 inputs and the 1 output as shown in figure 3, 4 and 5. This relationship between each input and the output was to show the changing pattern of the models based on the 'If...Then' rules generated by the system in figure 6 . 


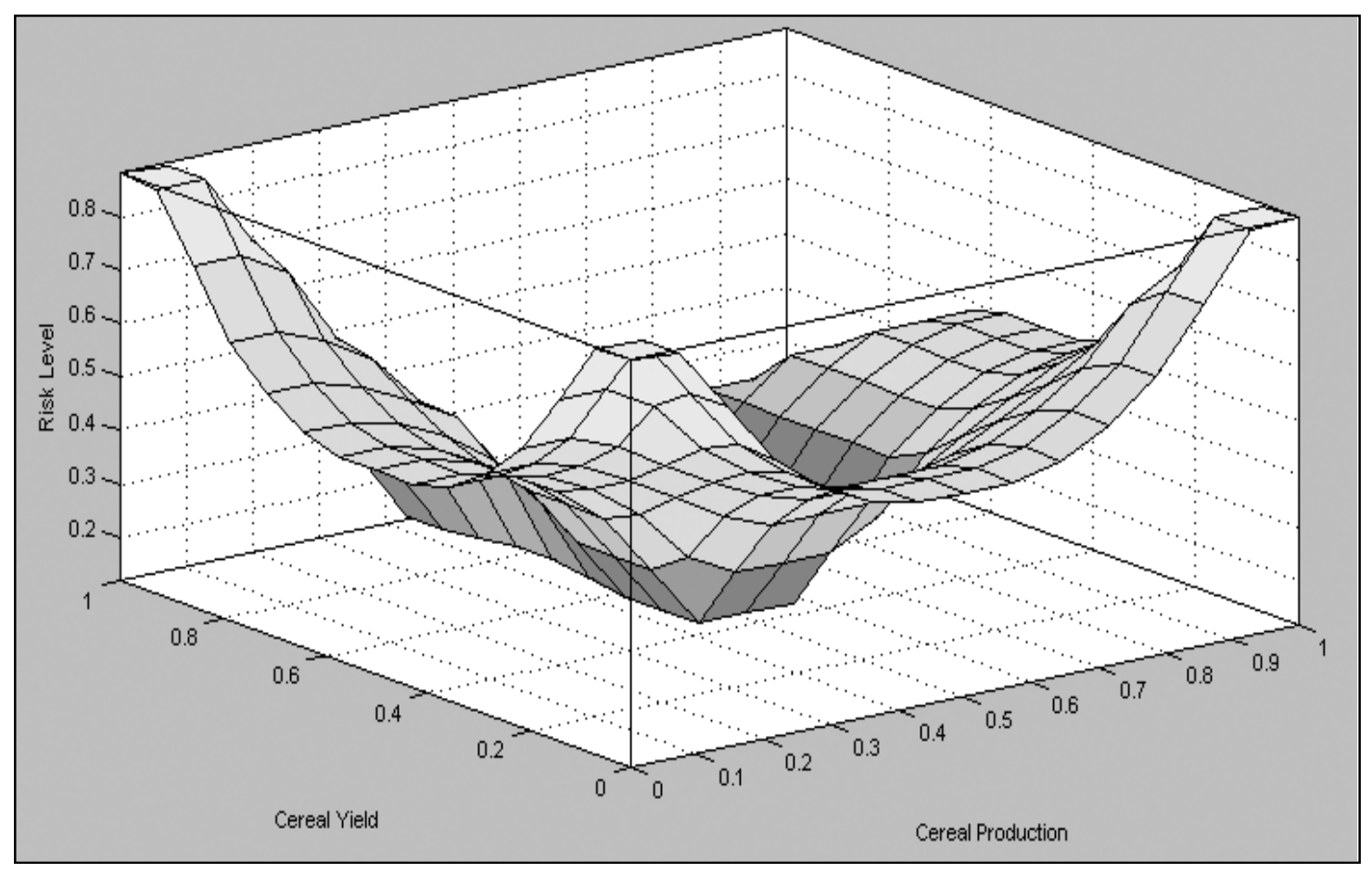

Figure 3: Output $=$ risk level, inputs $=$ cereal production and its yield

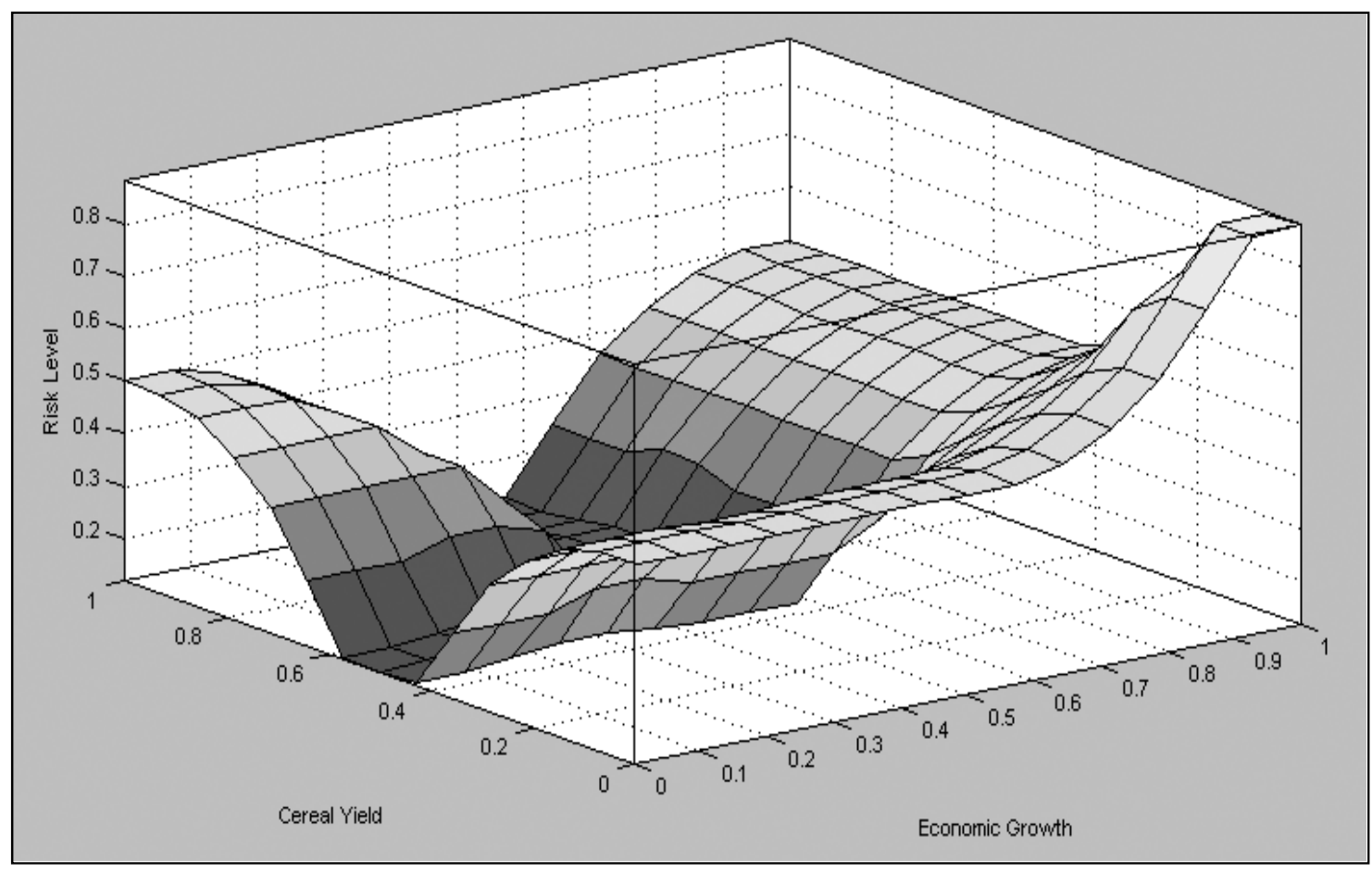

Figure 4: Output $=$ risk level, inputs $=$ Economic growth and cereal yield 


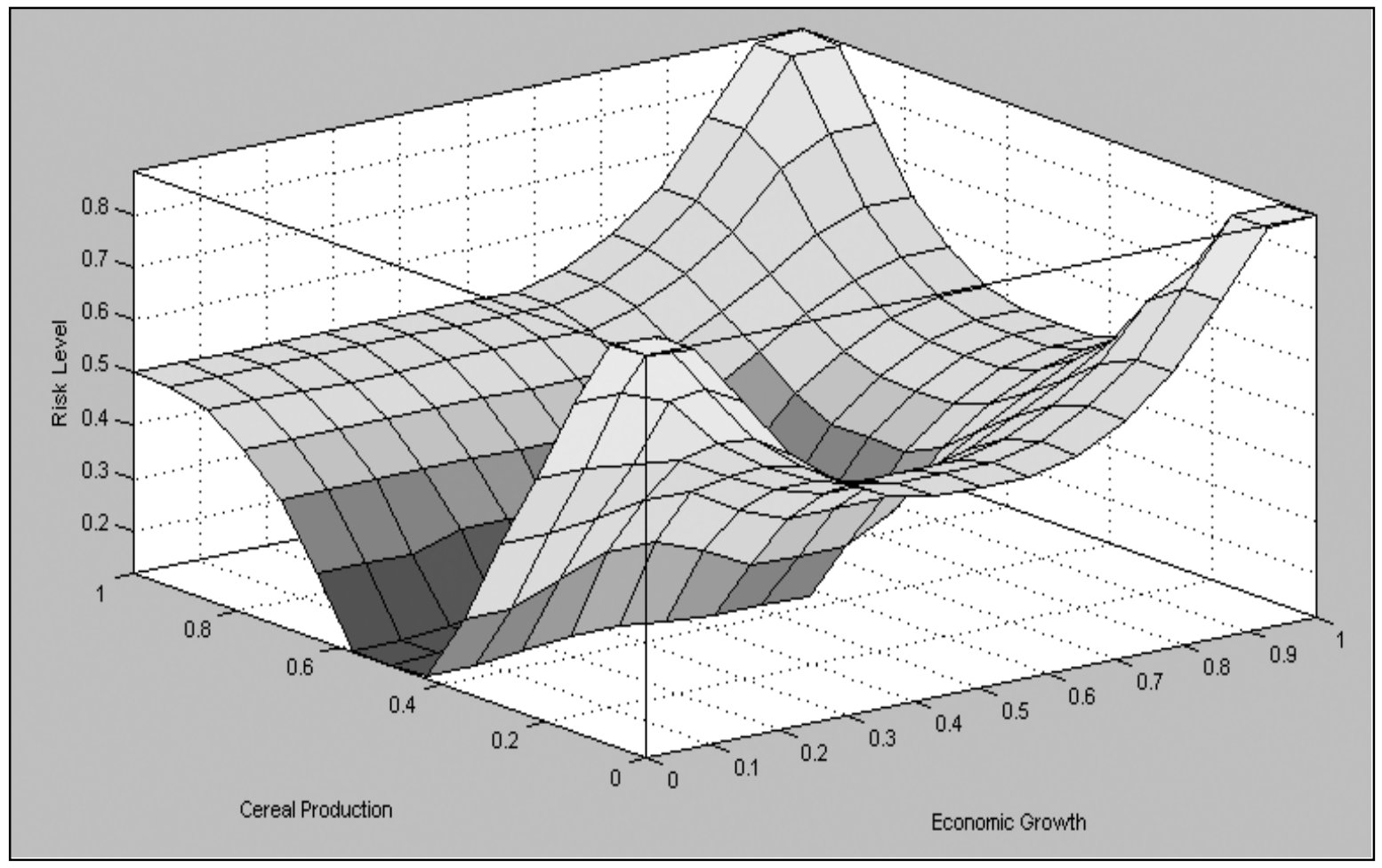

Figure 5: Output $=$ risk level, inputs $=$ Economic Growth and cereal production

The system output depends on the 27 rules, see table 3, that have been created. In order to clearly show the effect of the membership function, the results of all of the rules is shown in figure 6 where it shows the membership function used for each input and output. Figure 7 shows the overall membership function for each of the inputs and figure 8; it shows the membership function of the output. 


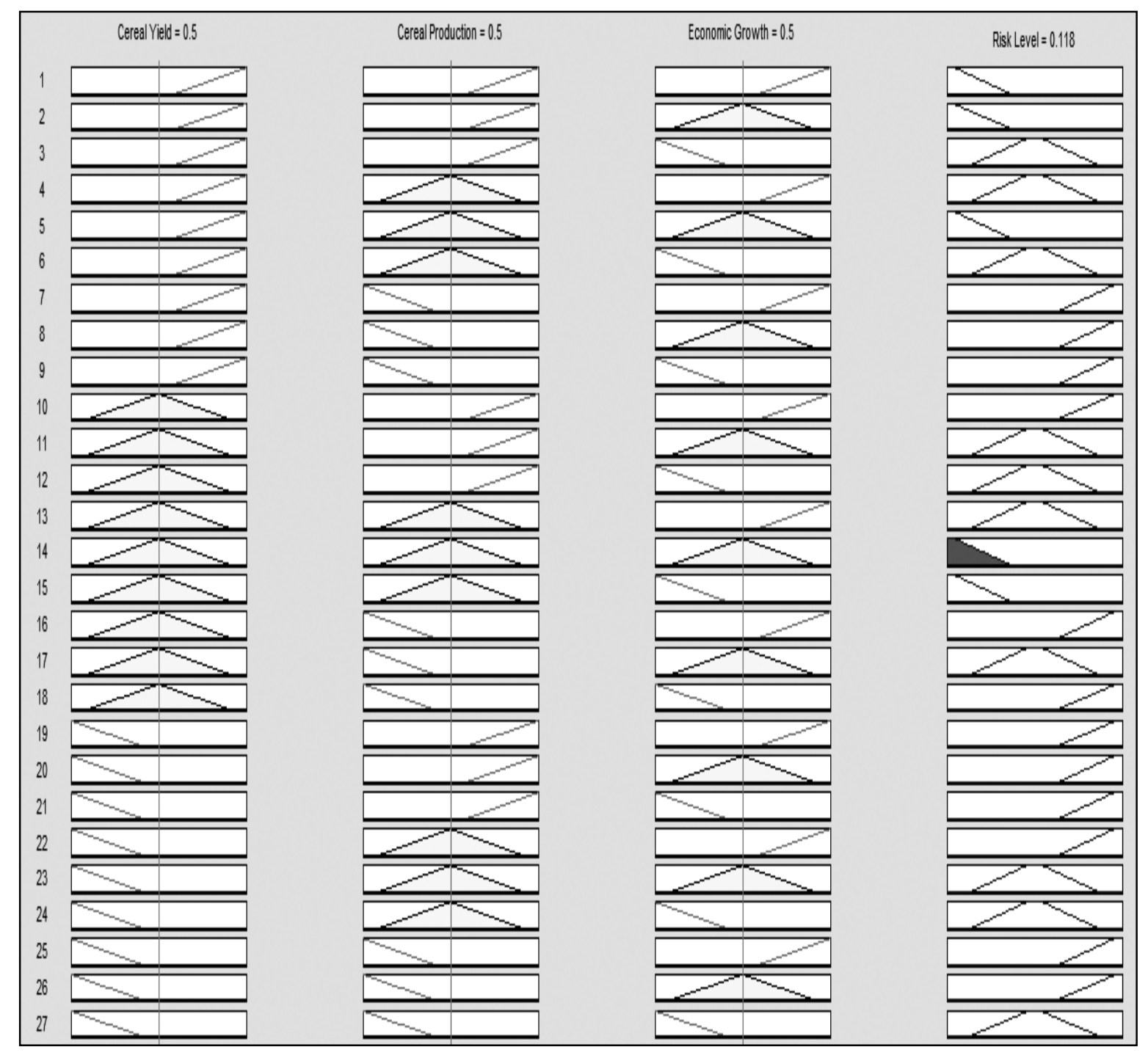

Figure 6: Rule evaluation for the 27 rules 


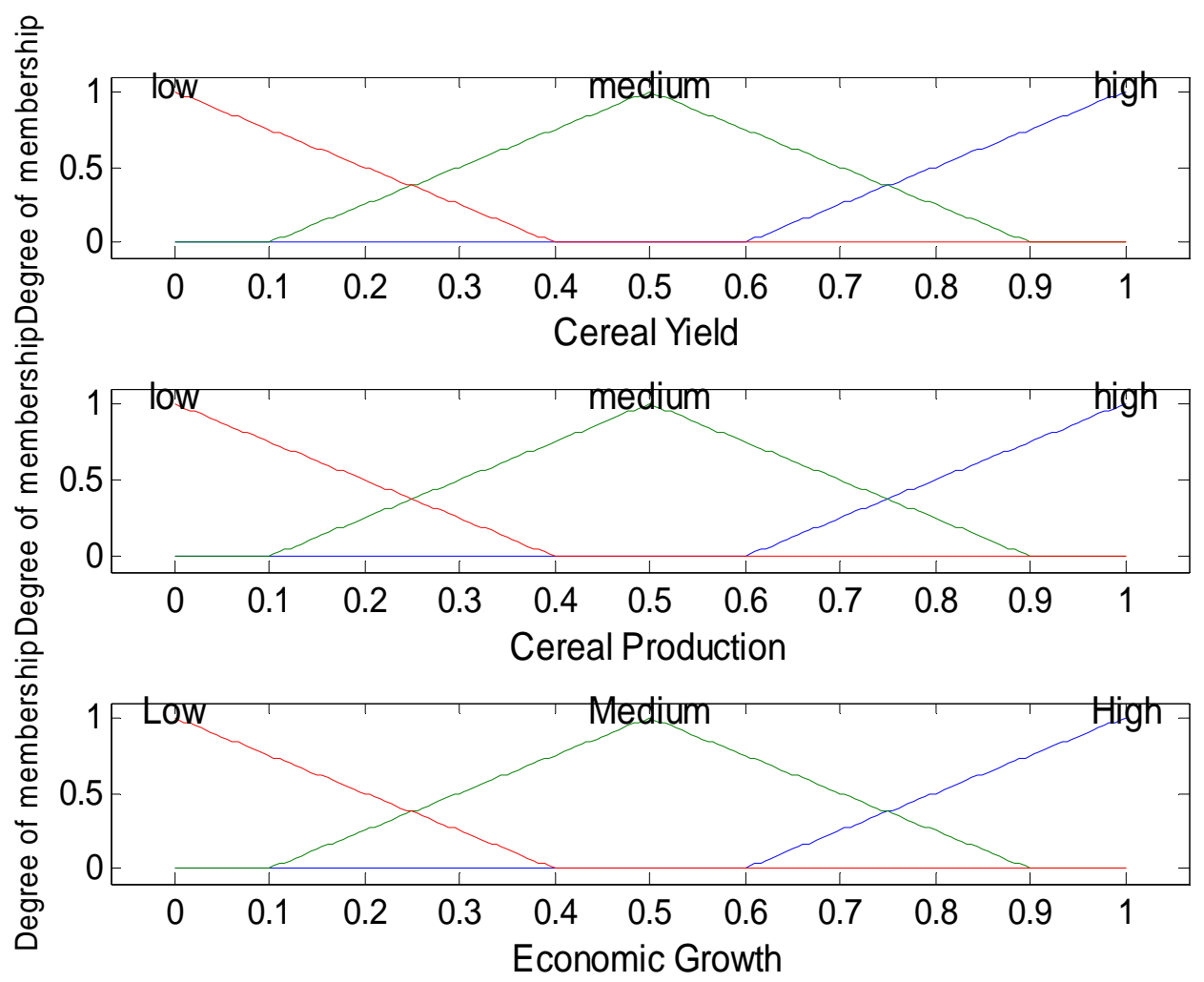

Figure 7: Plots for each input membership function and its range

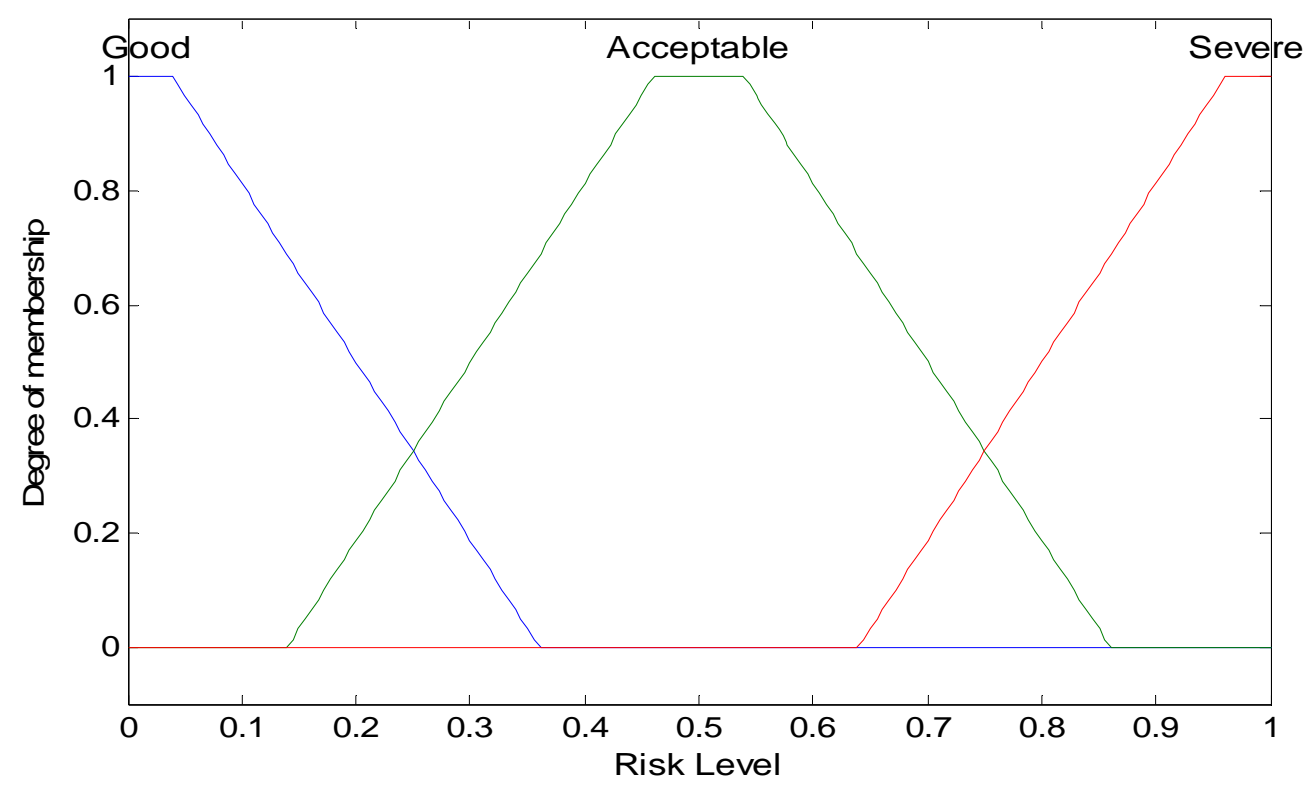

Figure 8: Plots for the output membership function and its range 
In order to verify the results, crisp outputs are used to test the system when real data is used as the inputs. The results show that every year the assessment of risk level of food security changed depending; cereal yield, cereal production and economic growth. For example in 1988, UK cereal yield was $53993 \mathrm{Hg} / \mathrm{Ha}$, cereal production was 21063000 tons and economic growth was 5.032\%. Hence from this, the result made the food security risk level value almost become 0.9 which is in severe condition.

Our system shows that although a high quantity of yield and high production should lead to high food security. However, when economic growth is low, people will try to pay the lowest price for their food which means the least resources are expended by the consumer in order to get the best food. Although some people will often prepared to pay for a given commodity even if they cannot afford it, it will not entirely effect on the system because it was assume to be in minor cases. So, an observation based on this is that the food is likely to be wasted; especially the high quality food which is most expensive. But, if the economic growth is high and the cereal yield is low, the food security is low and there may not be enough food for everyone. This relationship is shown in figure 9, where, based on the real data, for most years, the risk level is acceptable $(0.2-0.8)$. Only in 1992 and 1996 is a good (below 0.2) food security risk level. 


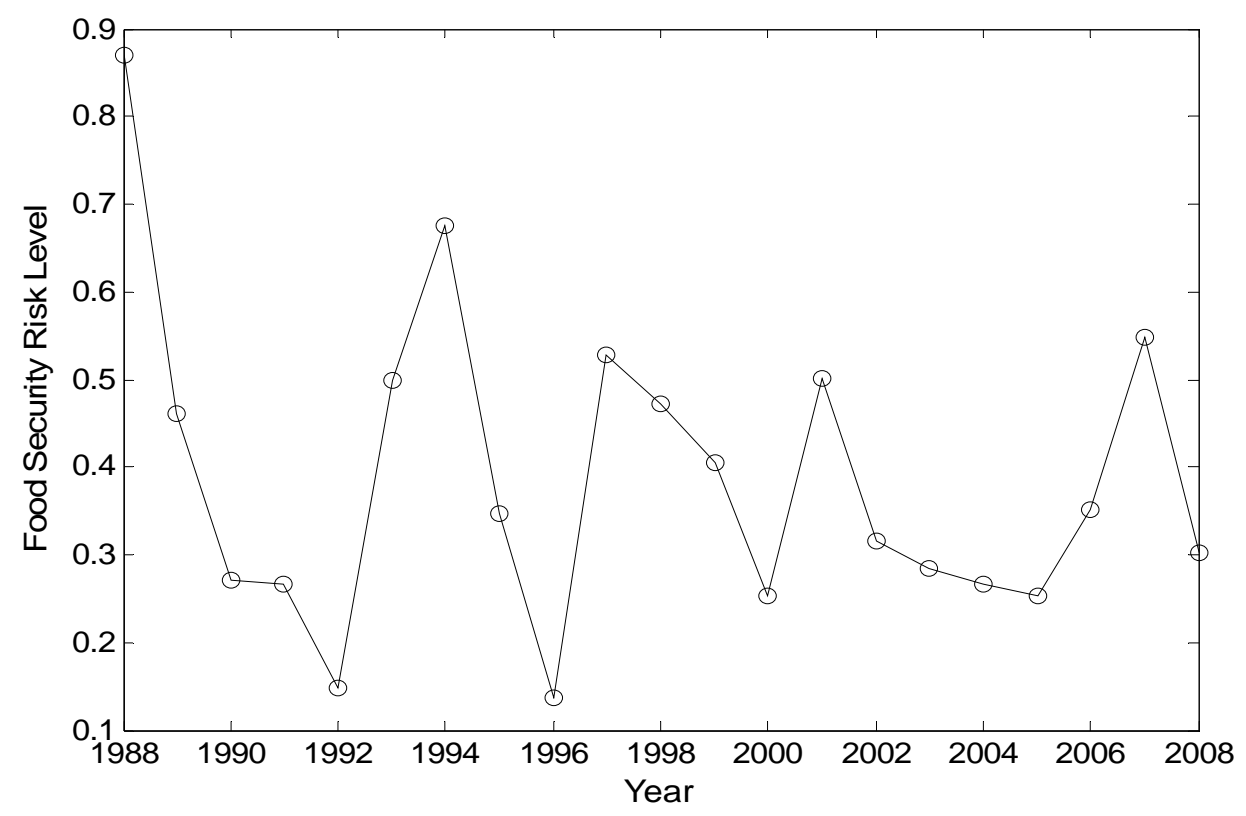

Figure 9: Simulation result for food security risk level for the years 1988 - 2008

\section{4 - Conclusions}

The work presented here has demonstrated how a FL based system might be used to predict food security risk levels using data which is relatively inconsistent. In this case, the study is concerned with the UK food security. Although the inputs were based on relatively poor quality information in terms of knowledge and the fact that we were using a weighting estimation which is equal to 1 where weighting estimation can be used to weight the importance of the input, in this study case, the inputs were given the same importance with each other. The FL can also be developed further to determine the risk level thoroughly and specifically. 


\section{Acknowledgements}

The authors wish to thank the support provided by EU Framework 7, Theme: KBBE2007-1-2-04, grant agreement no. 211457 and support given by Department for Environment Food and Rural Affairs (DEFRA) in providing the datasets, their help and cooperation in getting all the necessary information which have been used in this research. We would also wish to thank the School of Engineering, University of Warwick for their support. One of the authors also wishes to thank the Malaysian Government and Kuala Lumpur University for supporting him for the duration of his studies in the UK.

\section{References}

A.S. Sodiya, S.a.O., And B. A. Oladunjoye. 2007. Threat modeling using fuzzy logic paradigm. Informing Science and Information Technology 4.

World bank data http://databank.worldbank.org/ddp/home.do (accessed 2 July 2010).

Defra. 2009. Uk food security asessement: Out approach.: Department for Environment and Rural Affairs.

Defra. 2010. Uk food security asessement: Detailed analysis, ed. Department for Environment, FaRA: Department for Environment, Food and Rural Affairs.

Ding, Z.-H., J.-T. Li and B. Feng. 2007. Radio frequency identification in food supervision. In Advanced Communication Technology, The 9th International Conference on, 54245.

Faostat http://faostat.fao.org (accessed 2 July 2010).

Haslum, K., A. Abraham and S. Knapskog. 2007. Dips: A framework for distributed intrusion prediction and prevention using hidden markov models and online fuzzy risk 
assessment. In Information Assurance and Security, 2007. IAS 2007. Third International Symposium 183-90.

Huey-Ming, L. 1996. Applying fuzzy set theory to evaluate the rate of aggregative risk in software development. Fuzzy Sets and Systems 79, no. 3: 323-36.

Initiative, L.a.F.S. 2009. “L’aquila” joint statement on global food security: L’Aquila Food Security Initiative.

J.-S.R. Jang, C.-T.S., E. Mizutani. 1997. Neuo-fuzzy and soft computing: Prentice Hall.

J.S.R. Jang, N.G. 1997. Matlab: Fuzzy logic toolbox. The Math Works Inc.

Jianling, X. and D. Yong. 2010a. Food safety risk analysis based on generalized fuzzy numbers. In Advanced Management Science (ICAMS), 2010 IEEE International Conference on, 699-702.

Jianling, X. and D. Yong. 2010b. Linguistic ranking model and its application in food management. In Computer Design and Applications (ICCDA), 2010 International Conference on, V5-208-V5-12.

Jones, M.P. Achieving food security and economic growth in sub-saharan africa: Key institutional levers. In Forum for Agriculture Research Africa FARA.

M. Ahmend, E.D., Et Al. 1999. A general purpose fuzzy engine for crop control. Computational Intelligence 1625: 473-81.

Meltzer, H.M., A. Aro, N.L. Andersen, B. Koch and J. Alexander. 2003. Risk analysis applied to food fortification. Public Health Nutrition 6, no. 03: 281-90.

Negnevitsky, M. 2005. Artificial intelligence a guide to intelligent systems: Addison-Wesly.

Odetunji, O.A. and O.O. Kehinde. 2005. Computer simulation of fuzzy control system for gari fermentation plant. Journal of Food Engineering 68, no. 2: 197-207.

Organization, F.a.A. 2006. Food security : Policy brief ed. Organization, FaA: FAO. 
Peihong, C. and W. Jiaqiong. 2009. Application of a fuzzy ahp method to risk assessment of international construction projects, ed. Jiaqiong, W, 459-62.

Perrot, N., I. Ioannou, I. Allais, C. Curt, J. Hossenlopp and G. Trystram. 2006. Fuzzy concepts applied to food product quality control: A review. Fuzzy Sets and Systems 157, no. 9: 1145-54.

Xiaojun, W., L. Dong and S. Xianliang. 2008. A fuzzy enabled model for aggregative food safety risk assessment in food supply chains. In Service Operations and Logistics, and Informatics, 2008. IEEE/SOLI 2008. IEEE International Conference on, 2898-903.

Xie, G., R. Xiong and I. Church. 1998. Comparison of kinetics, neural network and fuzzy logic in modelling texture changes of dry peas in long time cooking. LebensmittelWissenschaft und-Technologie 31, no. 7-8: 639-47.

Yong, D. and X. Jianling. 2010. Fuzzy evidential warning of grain security. In Advanced Management Science (ICAMS), 2010 IEEE International Conference on, 703-06.

Zeng, J., M. An and N.J. Smith. 2007. Application of a fuzzy based decision making methodology to construction project risk assessment. International Journal of Project Management 25, no. 6: 589-600. 


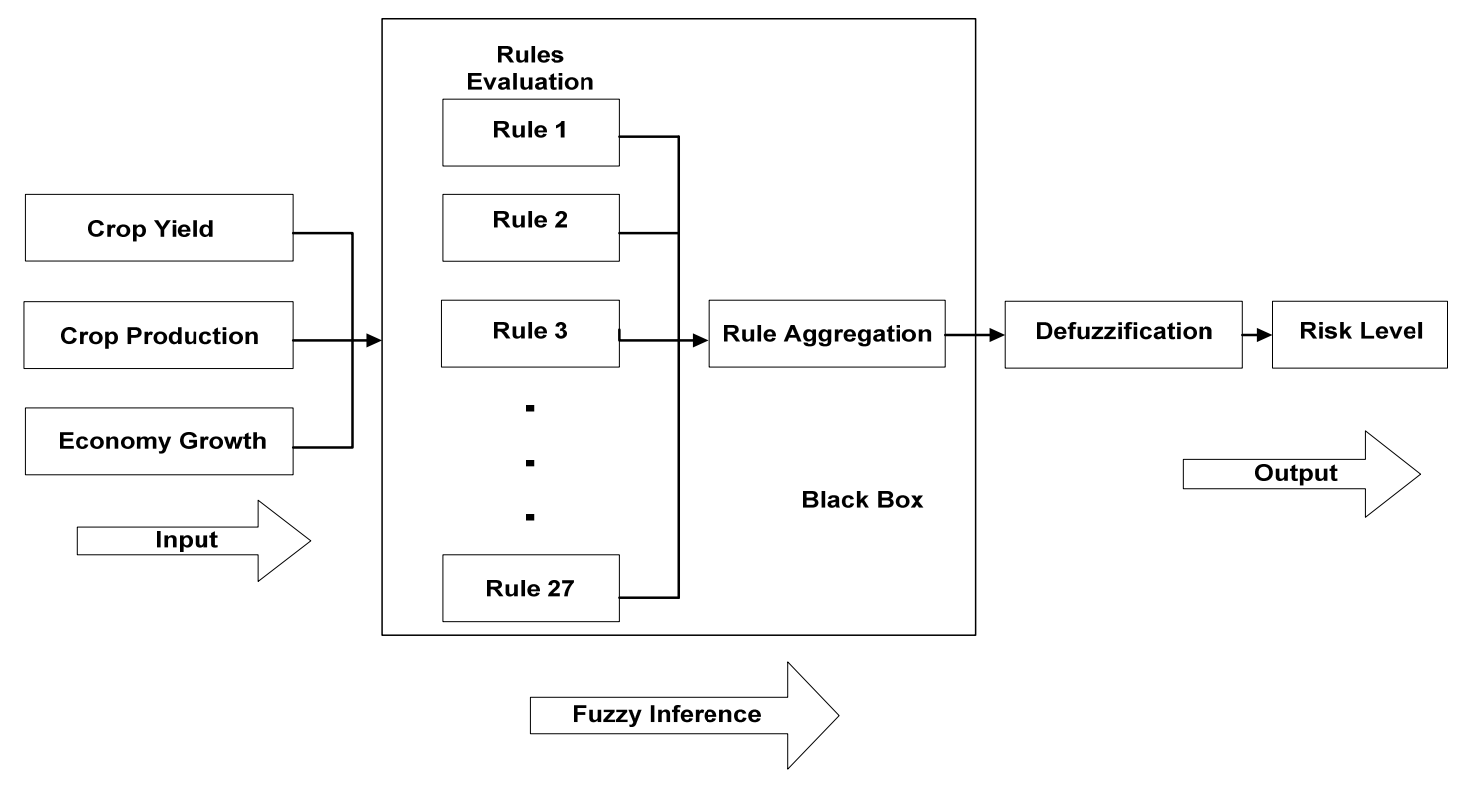

Figure 1: Basic block diagram of our FL system

\begin{tabular}{|c|c|c|}
\hline Input & Fuzzy set & Range \\
\hline Cereal Yield & High - Medium - Low & $0-1$ \\
\hline Cereal & High - Medium - Low & $0-1$ \\
Production & & \\
\hline Economic & High - Medium - Low & $0-1$ \\
Growth & & \\
\hline
\end{tabular}

Table 1: The input fuzzy sets and theirs range

\begin{tabular}{|c|c|c|}
\hline Output & Fuzzy set & Range \\
\hline Risk Level & Good -Acceptable - Severe & $0-1$ \\
& & \\
\hline
\end{tabular}

Table 2: The output fuzzy sets and theirs range 


\begin{tabular}{|c|c|c|c|}
\hline \multicolumn{3}{|c|}{ Input } & \multirow{2}{*}{$\begin{array}{c}\text { Output } \\
\text { Food Security Risk Level }\end{array}$} \\
\hline Cereal Yield & Cereal Production & Economic Growth & \\
\hline High & High & High & Good \\
\hline High & High & Medium & Good \\
\hline High & High & Low & Acceptable \\
\hline High & Medium & High & Acceptable \\
\hline High & Medium & Medium & Good \\
\hline High & Medium & Low & Acceptable \\
\hline High & Low & High & Severe \\
\hline High & Low & Medium & Severe \\
\hline High & Low & Low & Severe \\
\hline Medium & High & High & Severe \\
\hline Medium & High & Medium & Acceptable \\
\hline Medium & High & Low & Acceptable \\
\hline Medium & Medium & High & Acceptable \\
\hline
\end{tabular}




\begin{tabular}{|c|c|c|c|}
\hline Medium & Medium & Medium & Good \\
\hline Medium & Medium & Low & Good \\
\hline Medium & Low & High & Severe \\
\hline Medium & Low & Medium & Acceptable \\
\hline Medium & Low & Low & Severe \\
\hline Low & High & High & Severe \\
\hline Low & High & Medium & Severe \\
\hline Low & High & Low & Severe \\
\hline Low & Medium & High & Severe \\
\hline Low & Medium & Medium & Acceptable \\
\hline Low & Medium & Low & Acceptable \\
\hline Low & Low & High & Severe \\
\hline Low & Low & Medium & Severe \\
\hline Low & Low & Low & Acceptable \\
\hline
\end{tabular}

Table 3: Rule list showing the connection between the inputs and the output 


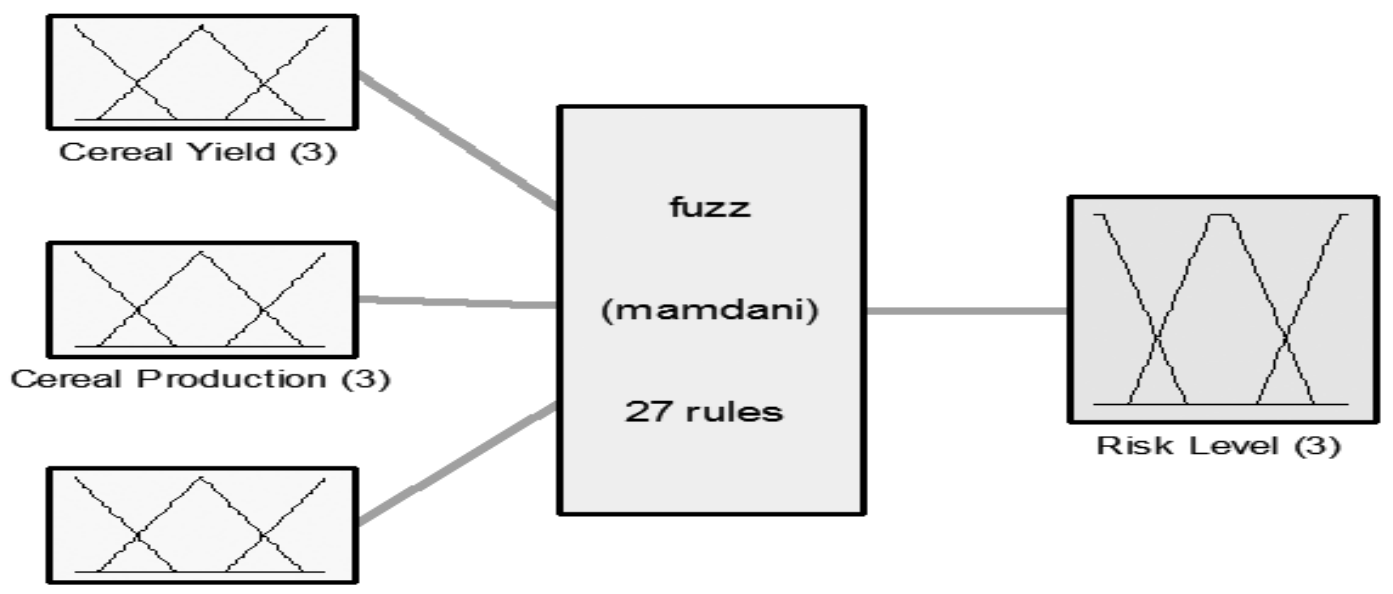

Economic Growth (3)

System fuzz: 3 inputs, 1 outputs, 27 rules

Figure 2: The model for our FL-based risk assessment system

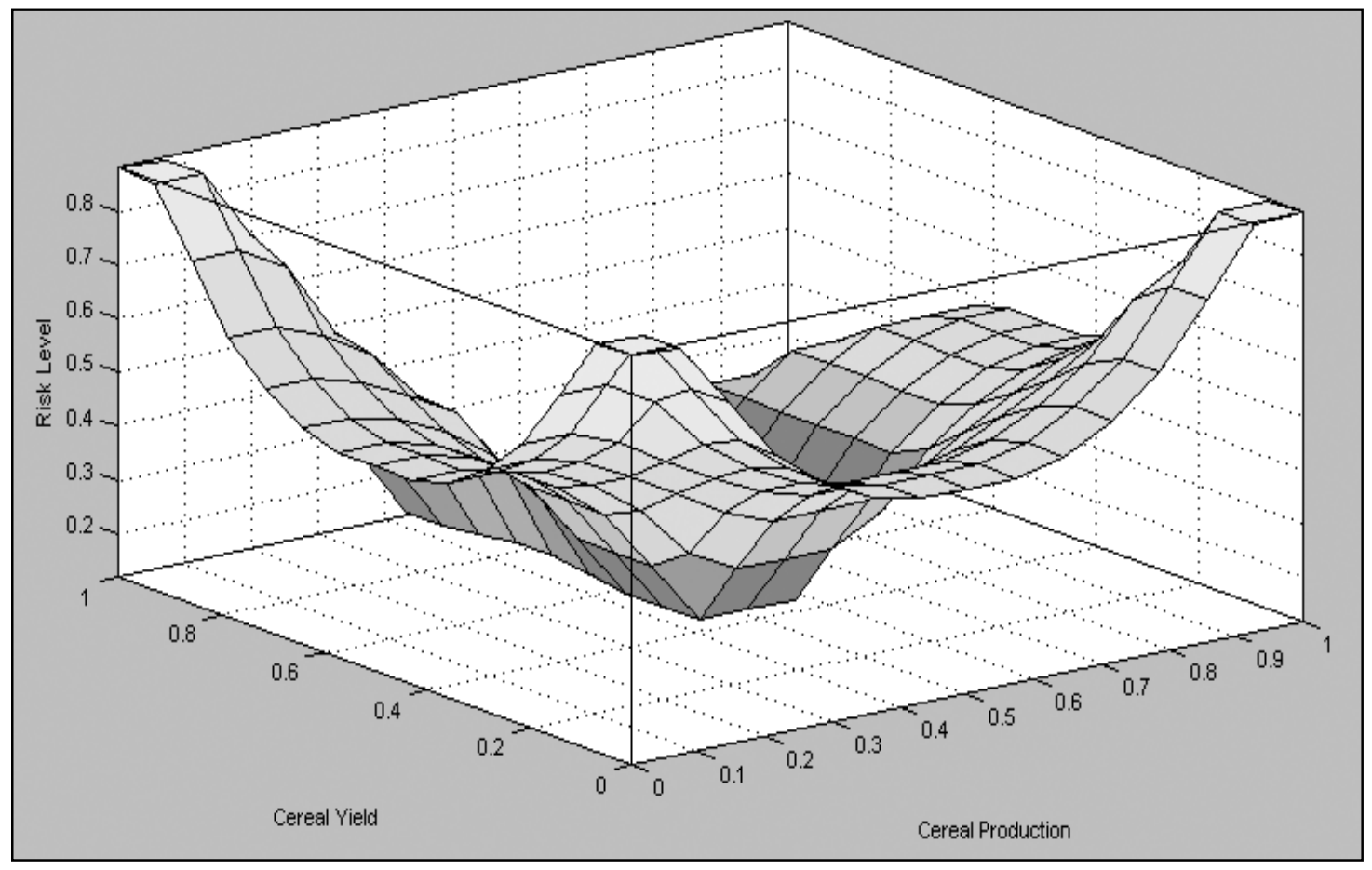

Figure 3: Output $=$ risk level, inputs $=$ cereal production and its yield 


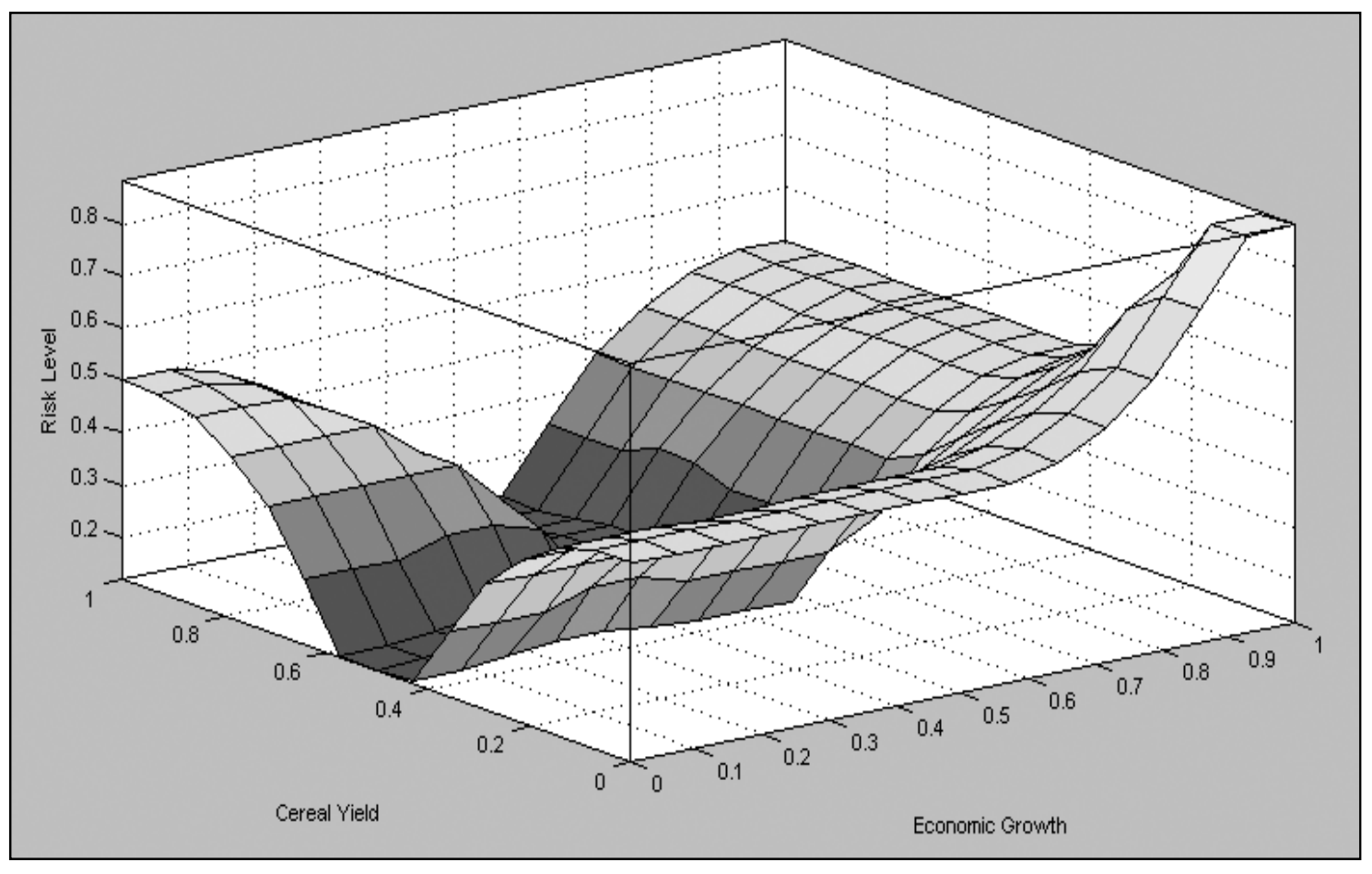

Figure 4: Output = risk level, inputs = Economic growth and cereal yield

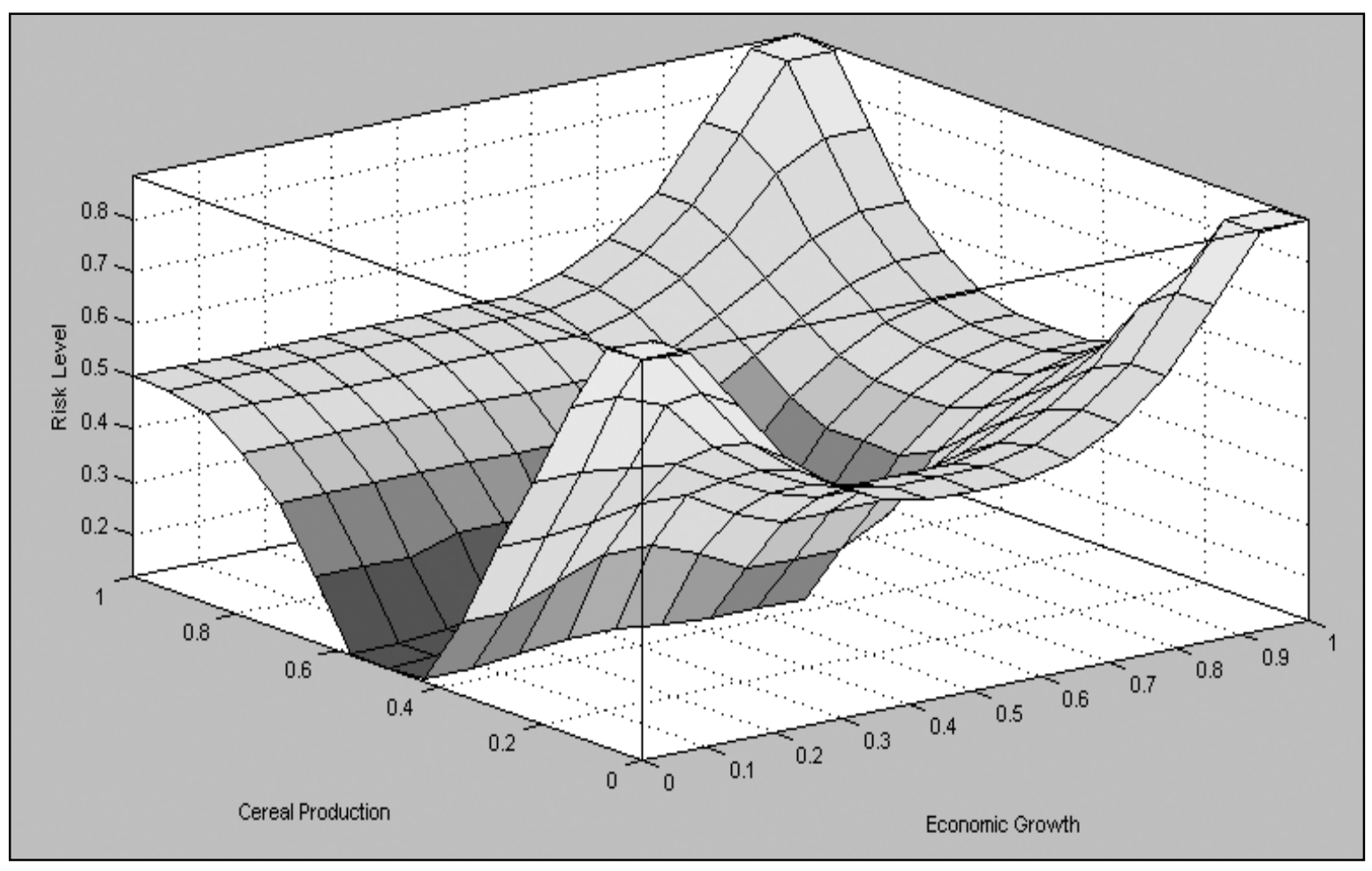

Figure 5: Output $=$ risk level, inputs $=$ Economic Growth and cereal production 


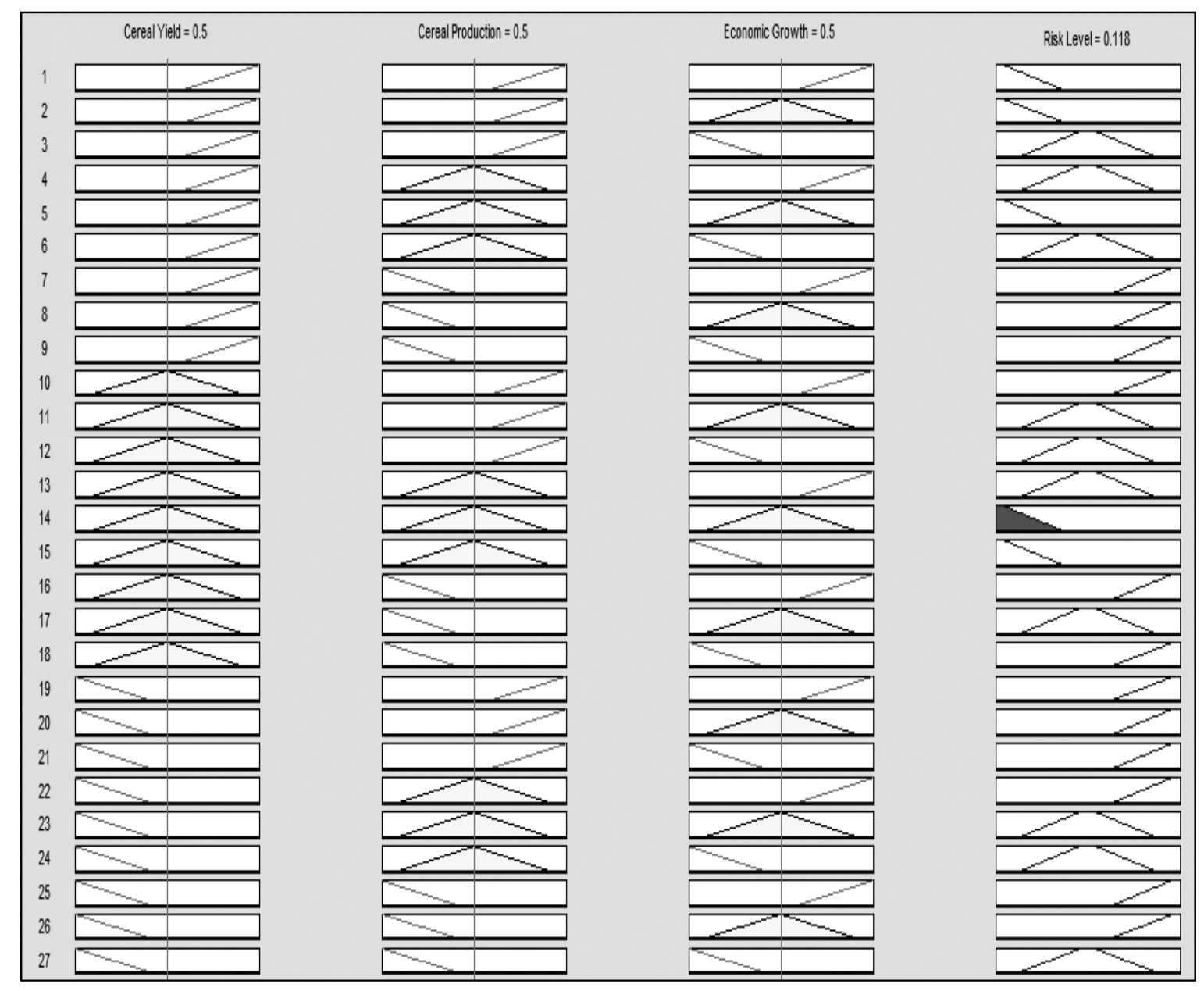

Figure 6: Rule evaluation for the 27 rules 


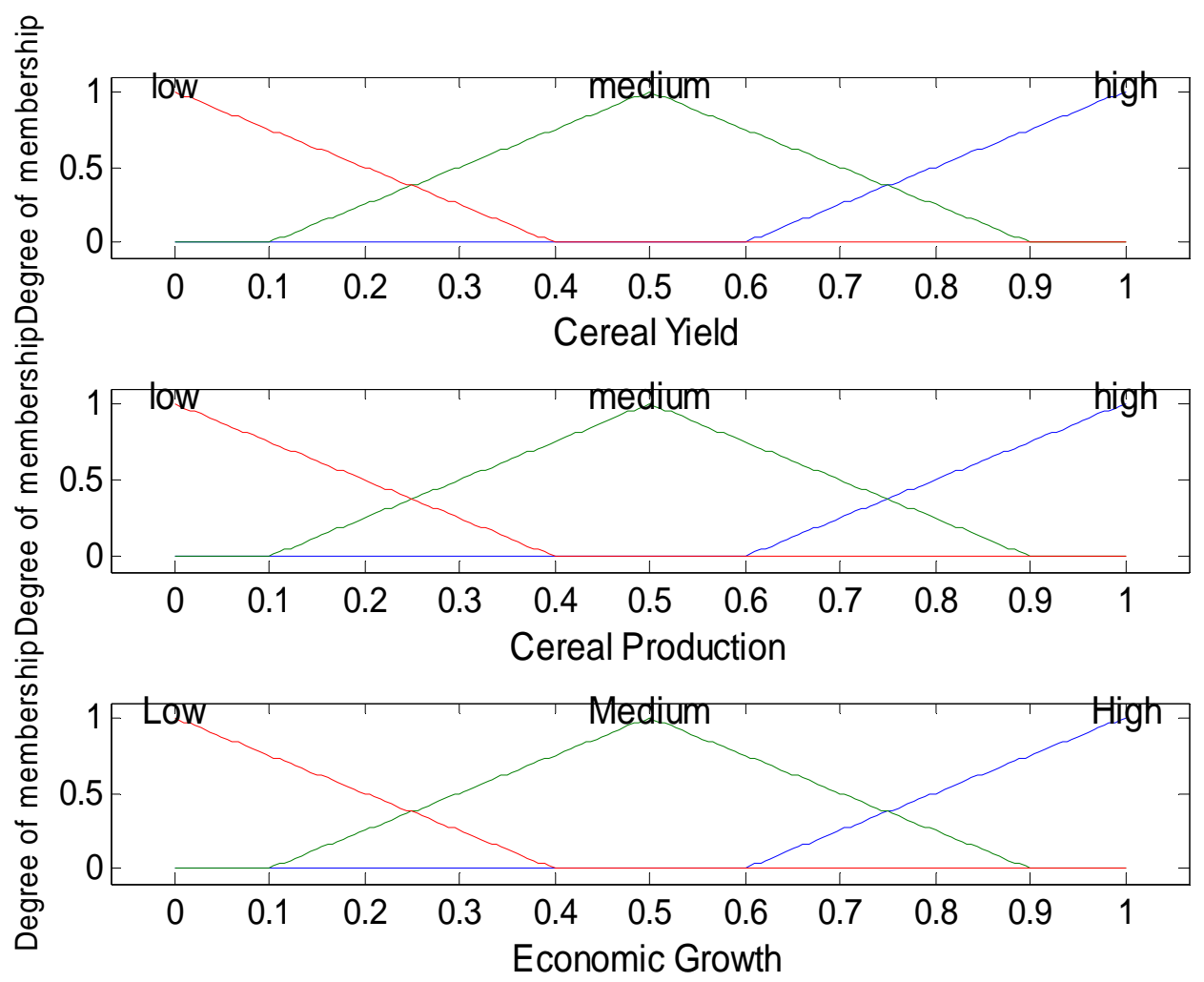

Figure 7: Plots for each input membership function and its range

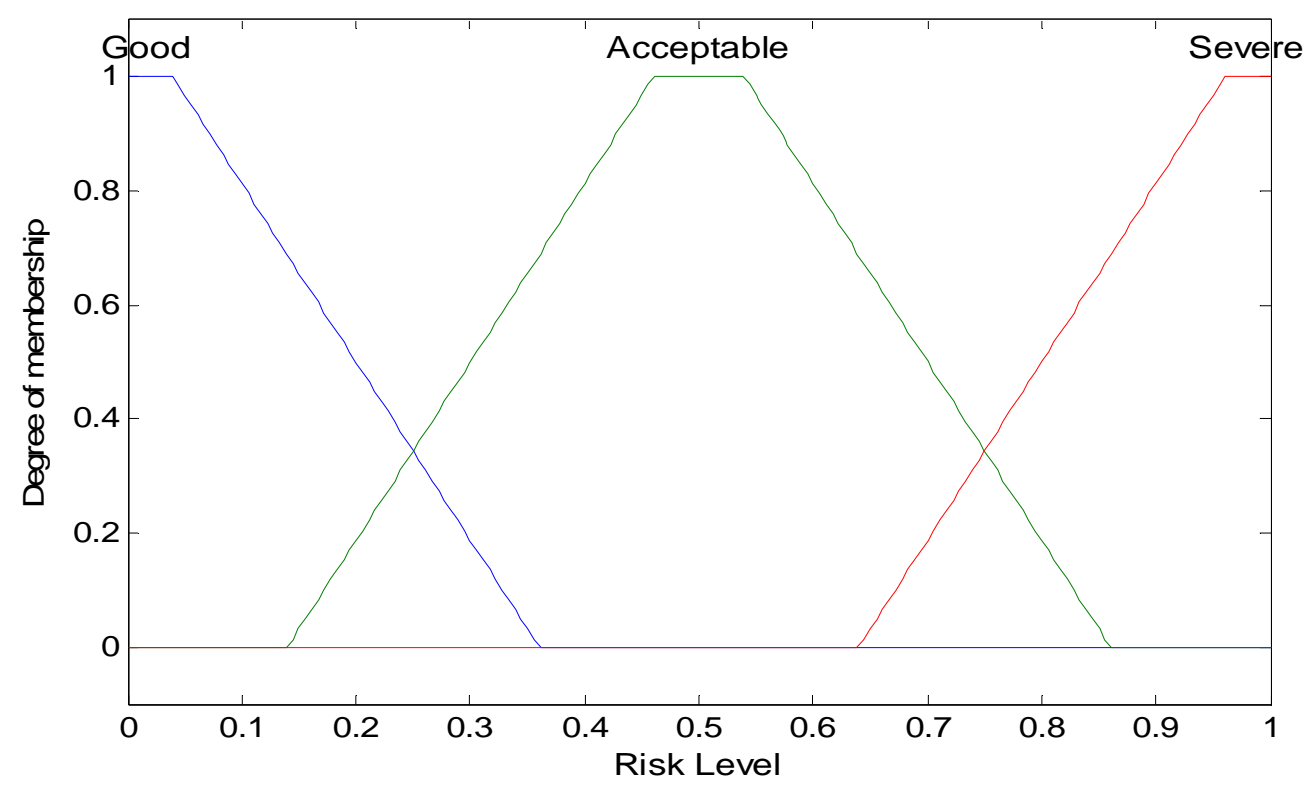

Figure 8: Plots for the output membership function and its range 


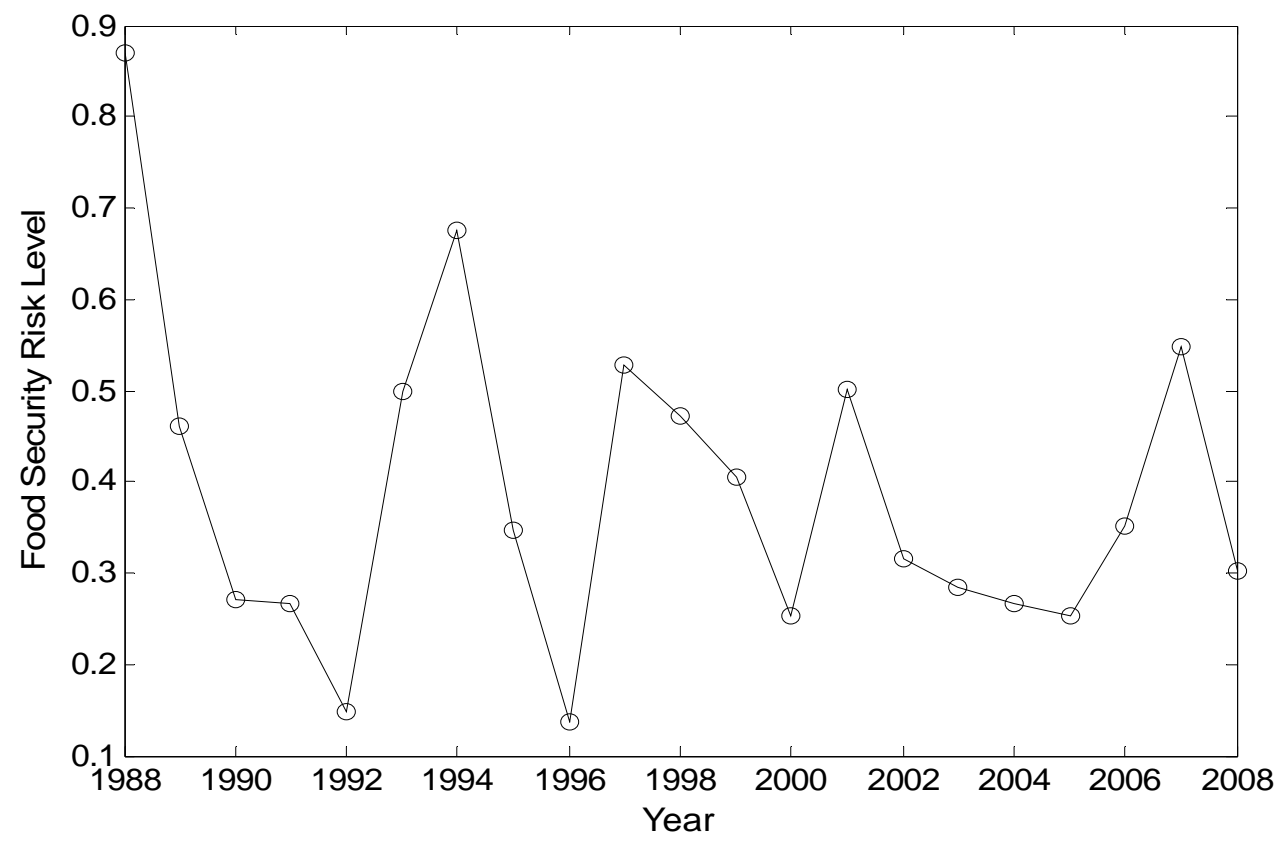

Figure 9: Simulation result for food security risk level for the years 1988 - 2008 